\title{
Evaluation of Knowledge regarding Shaken Baby Syndrome among Parents in Tabuk City

\author{
Abdullah Nasser Alshahrani ${ }^{1}$, Mohammed Nasser Alshahrani ${ }^{2}$, \\ Ali Bani Ahmed ${ }^{2}$ \\ ${ }^{1}$ Faculty of Medicine Tabuk University, ${ }^{2}$ Faculty of Applied Medical Sciences, Tabuk University
}

\begin{abstract}
Background: abusive head trauma (AHT) or shaken baby syndrome (or SBS), is an injury to a child's brain as a result of abuse. SBS can be caused by direct blows to the head, dropping, throwing or shaking a child. The prevalence of SBS has been reported to be 14-33.8/100 000 in children aged below one year. With a mortality rate of approximately $25 \%$, a great portion of the survivors continue their lives with functional disorders including learning difficulty, behavior problems, advanced cognitive and developmental retardation, stroke and blindness. Shaking frequently occurs as a result of getting angry of a caregiver of a baby who cries in an unspecifiable way. Therefore, caregivers of babies should be aware of their level of stress and learn how to cope with stress. Shaken baby syndrome is a preventable problem. However, we have limited knowledge about how educated of caregivers about SBS especially in less urbanized regions such as Northern Borders including Tabuk city. Aim of the Work: to evaluate parents' knowledge regarding shaking baby syndrome in Tabuk city. Patients and Methods: The target population of this research are parents who have children up to one year old in Tabuk city. A questionnaire was administered to parents who have children from birth up to one year old. The participants were consented and then the questionnaires were distributed to them. The questionnaires involved questions regarding some demographics including age, educational level, nationality, how many children. Questions regarding Level of knowledge about SBS included: incidents of shaking their baby during the first year of life, awareness about the risk of shaking your child in first year, knowledge about the term shaking baby syndrome. All data obtained with questionnaire were analyzed using the Statistical Package for the Social Sciences (SPSS) version 23. The chi square statistics were used to test our hypotheses and the distributions of categorical variables. Results: The total sample size was 92 participants. Descriptive statistics showed that $88 \%$ were Saudi, $60 \%$ were below the age of 40 . Regarding education, $12 \%$ were illiterate. Regarding the knowledge about SBS, $57.61 \%$ reported shaking the baby to make them quite within the 1 st year of life. $67.39 \%$ reported said they had no idea about the risks of shaken the baby during the 1 st year of life. Moreover, about $70 \%$ reported they have never heard about what is called SBS. Conclusion: Majority of parents have never heard about SBS. Only 32\% of the surveyed understood the connection of shaking with risks on the child's life during the 1st year and thereafter. Perception, knowledge of and attitudes towards SBS must be addressed by applying Shaken Baby Syndrome educational and Prevention Programs especially in less urbanized regions such as Northern Borders including Tabuk city.
\end{abstract}

Keywords: Shaken Baby Syndrome, childhood head injury, craniocerebral trauma, inflicted traumatic brain injury.

\section{INTRODUCTION}

Abusive head trauma (AHT) is an injury to a child's brain.as a result of child abuse. It can be caused by direct blows to the head, dropping or throwing a child, or shaking a child. AHT is also called shaken baby syndrome (or SBS), inflicted traumatic brain injury, and shaken impact syndrome ${ }^{1}$. In a few epidemiological studies, the prevalence of SBS has been reported to be $14-33.8 / 100000$ in children aged below one year. It is thought that these figures are lower than the actual ones because of problems in reporting ${ }^{2,3}$. Approximately $25 \%$ of the subjects are lost in a few days after injury. A great portion of the survivors continue their lives with functional disorders including learning difficulty, behavior problems, advanced cognitive and developmental retardation, stroke and blindness. No dysfunction is found in only less than $35 \%$ of all cases ${ }^{4}$. Shaking frequently occurs as a result of getting angry of a caregiver of a baby who cries in an unpacifiable way. Therefore, caregivers of babies should be aware of their level of stress and learn how to cope with stress ${ }^{5}$. Shaken baby syndrome is a preventable problem. Prevention has become important, because it is late when the child is shaken and abused ${ }^{6}$. Education is given to prevent this syndrome in the world especially in developed countries $^{7}$. During this education, it is important to 
explain to everybody who takes care of babies that crying is a normal part of the baby's development, to teach coping with a crying baby and pacifying methods and to give information about the harms of shaking ${ }^{8}$. In Shaken Baby Syndrome prevention programs (SBSPP), education is recommended to be given before $2-4$ months which is the period when the frequency of crying of babies is increased. It is important to mention that the education given in the early period is permanent until the time when the frequency of crying is increased ${ }^{8}$. Abusive head trauma (AHT) is an injury to a child's brain as a result of child abuse. It can be caused by direct blows to the head, dropping or throwing a child, or shaking a child. AHT is also called shaken baby syndrome (or SBS), inflicted traumatic brain injury, and shaken impact syndrome ${ }^{9}$. Head trauma is the leading cause of death in child abuse cases in the United States. Because the anatomy of infants puts them at particular risk for injury from this kind of action, the majority of victims are infants younger than 1 year old ${ }^{9}$. AHT can happen in children up to 5 years old, but the average age of victims is between 3 and 8 months. The highest rate of cases is among infants just 6 to 8 weeks old, which is when babies tend to cry the most ${ }^{9}$. In a few epidemiological studies, the prevalence of SBS has been reported to be 14-33.8/100 000 in children aged below one year. It is thought that these figures are lower than the actual ones because of problems in reporting ${ }^{2,3}$. In the Present study we aimed to evaluate parents' knowledge regarding shaking baby syndrome in Tabuk city.

\section{AIM OF THE WORK}

To evaluate parents' knowledge regarding shaking baby syndrome in Tabuk city.

\section{PATIENTS AND METHODS}

The target population of this research was parents who have children up to one year old in Tabuk city. A questionnaire was administered to parents who have children from birth up to one year old. The participants were consented and then the questionnaires were distributed to them. The questionnaire involved questions regarding some demographics including age, educational level, nationality, how many children. Questions regarding Level of knowledge about SBS included: incidents of shaking their baby during the first year of life, awareness about the risk of shaking your child in first year, knowledge about the term shaking baby syndrome. All data obtained with questionnaires were analyzed using the Statistical Package for the Social Sciences (SPSS) version 23. The chi square statistics were used to test our hypotheses and the distributions of categorical variables. Data Collection: The researchers approached parents with children from birth up to one year old. The researchers are going to explain the study to the parents to take their consent and then distribute the questionnaires to them. Ethical Considerations: The research was conducted according to the ethical principles of medical research developed by the World Medical Association Declaration of Helsinki. Approval was obtained from the Research Committee (Faculty of applied medical sciences / University of Tabuk). Informed consents was obtained from the parents before entry into the study. Statistical Analysis: All data that have been obtained with questionnaires were analyzed using the Statistical Package for the Social Sciences (SPSS) version23. The chi square test was used to test distribution of categorical variables and student's $t$ test for continuous variables. Statistical significance was accepted when $P$ value was less than 0.05 .

\section{RESULTS}

The total sample size was 92 participants. Descriptive statistics showed that $88 \%$ were Saudi, $60 \%$ were below the age of $40 \mathrm{yrs}$. old. With regard to education, $12 \%$ were illiterate.
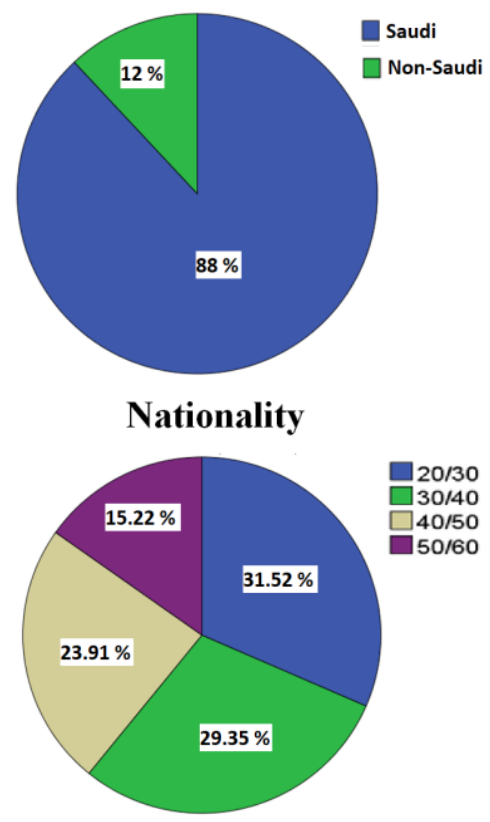

Age range 
Abdullah Nasser Alshahrani et al.

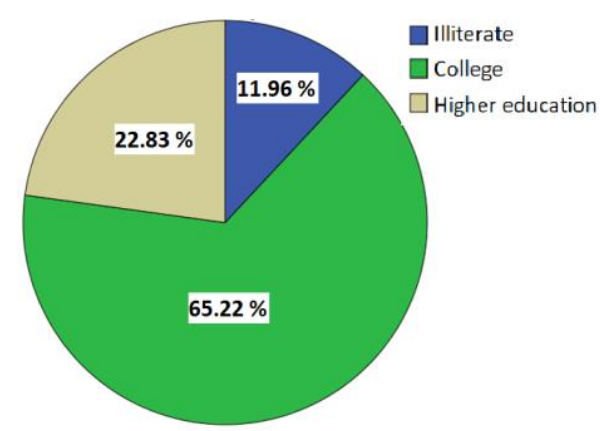

Level of Education

\section{Knowledge about SBS}

Are you aware of the risks of shaking a baby during the $\mathbf{1}^{\text {st }}$ year of life?

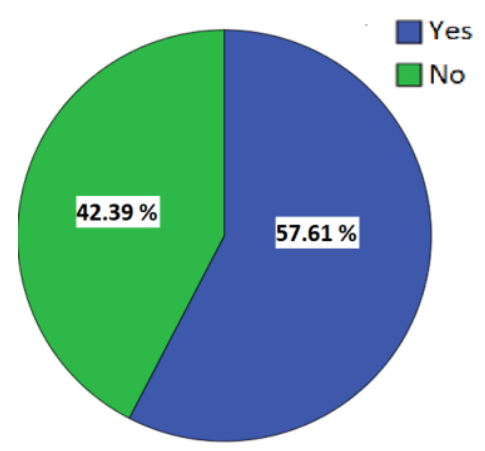

Are you aware of the risks of shaking a baby during the $1^{\text {st }}$ year of life?

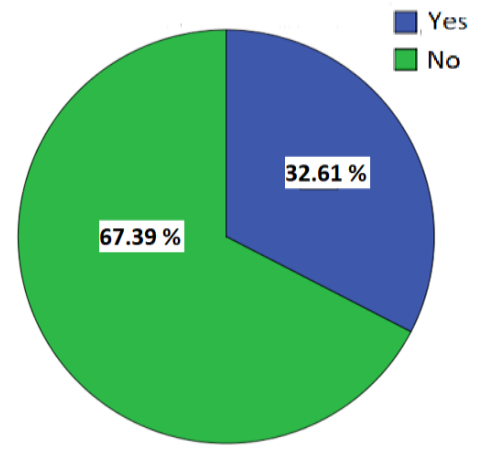

Have you ever heard about the term Shaken baby Syndrome (SBS)

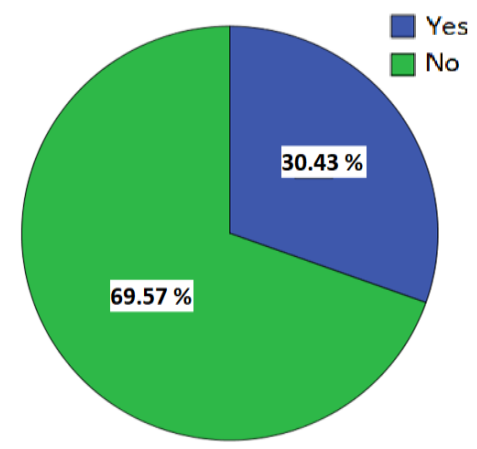

$57.61 \%$ reported shaking the baby to make them quite within the 1st year of life. $67.39 \%$ reported said they had no idea about the risks of shaken the baby during the 1 st year of life. Moreover, about $70 \%$ reported they have never heard about what is called SBS.

\section{DISCUSSION}

The kingdom of Saudi Arabia has urbanized rapidly in the last half of the 20th century. About $80 \%$ of Saudis live in urban metropolitan areas-specifically Riyadh, Jeddah, or Dammam ${ }^{10}$. However, Areas like Tabuk city are considered of the rural provinces with a subsistence life. Therefore, it was our aim in this study to shed some light with regard to knowledge and attitude towards SBS in less urbanized regions such as Northern Borders including Tabuk city. Moreover, the state of knowledge of the SBS phenomenon is a major concern worldwide as it was reported to be a high concern even in parents in the medical field who are expected to be the most knowledgable about this phenomenon ${ }^{11}$. As predicted, the state of knowledge regarding SBS was poor as majority of the parents members have never heard about SBS. Only $32 \%$ of the surveyed participants understood the connection between shaking the child and the risks on the child live during the 1st year of life and thereafter. The results demonstrated deficiency of knowledge with regard to SBS and its consequences. Conclusively, Perception, knowledge and attitude towards SBS must be addressed by applying Shaken Baby Syndrome educational and prevention programs especially in less urbanized regions such as Northern Borders including Tabuk city to increase awareness of the community about this important phenomenon.

\section{CONFLICTS OF INTEREST}

There are no conflicts of interest.

\section{REFERENCES}

1. American Academy of Pediatrics (2001): Committee on Child Abuse and Neglect Shaken baby syndrome: rotational cranial injuries-technical report. Pediatrics, 108:206-210.

2. Kelly P, Farrant B (2008): Shaken baby syndrome in New Zealand, 2000-2002. Journal of Paediatrics and Child Health, 44:99-107. 
3. Minns RA, Jones PA, Mok JYQ (2008): Incidence and demography of nonaccidental head injury in southeast scotland from a national database. American Journal of Preventive Medicine, 34:S126-S133.

4. Jacobi G, Dettmeyer R, Banaschak S, Brosig B, Herrmann B (2010): Child Abuse and Neglect: Diagnosis and Management. Dtsch Arztebl Int., 107:231-40.

5. Reijneveld SA, van der Wal MF, Brugman E, Hira Sing RA, Verloove-Vanhorick SP (2004): Prevalence of parental behaviour to diminish the crying of infants that may lead to abuse. Ned Tijdschr Geneeskd., 148:2227-30.

6. Showers J (1992): Don't shake the baby: the effectiveness of a prevention program. Child Abuse Negl., 16:11-8.

7. Overpeck MD, Brenner RA, Trumble AC, Trifiletti LB, Berendes HW (1998): Risk factors for infant homicide in the United States. N Engl J Med., 339:1211-6.

8. Deyo G, Skybo T, Carroll A (2008): Secondary analysis of the "Love Me...Never Shake Me" SBS education program. Child Abuse Negl., 32:1017-1025.
9. Christian CW, Block R (2009): Abusive head trauma in infants and children. Pediatrics, 123:1409-1411

10. House KE (2013): On saudi arabia: Its people, past, religion, fault lines--and future. Vintage Books, https://books.google. com.eg/books?id=T23dCwAAQBAJ\&pg= PA29\&lpg=PA29\&dq=The+kingdom+of + Saudi+Arabia+has+urbanized+rapidly+in $+\mathrm{t}$ he+last + half + of + the +20 th+century.+About $+80 \% 25+$ of + Saudis+live+in+urban+metro politan+areas $\% \mathrm{E} 2 \% 80 \% 94$ specifically+Ri yadh,+Jeddah, + or + Dammam \&source $=$ bl \& ots $=$ OJ9 $\mathrm{wdPphoV} \&$ sig=DmgrNsdon2IDD bvZhuyPid9DJmc\&hl=en\&sa $=X \& v e d=2 a h$ UKEwjO-5md4fncAhVHZFAKHahBBZE Q6AEwAHoECAIQAQ\#v=onepage $\& \mathrm{q}=8$ $0 \% 25 \% 20$ of $\% 20$ Saudis $\% 20$ live $\% 20$ in $\% 20$ urban\%20metropolitan\%20areas \&f=false

11. Marcinkowska U, Tyrala $K$, Paniczek M, Ledwon M, Josko-Ochojska J (2016): Evaluation of knowledge regarding shaken baby syndrome among parents and medical staff. Minerva Pediatr., 61(6):1693-1696. 